\title{
Implantation-induced changes in uterine arylamidase localization in the rabbit, rat, hamster and guinea-pig
}

\author{
J. A. Mitchell* and H.-W. Denker \\ Abteilung Anatomie der RWTH Aachen, Melatener Strasse 211, D-5100 Aachen, West Germany
}

\begin{abstract}
Summary. Localization of uterine arylamidase activity varied between species: arylamidase was found primarily in the apical aspect of uterine epithelial cells in the rabbit, hamster and non-pregnant rat; only moderate staining was observed in these animals in the endometrial stroma. By contrast, arylamidase localization was primarily stromal in the guinea-pig at all stages studied while the luminal epithelium was devoid of reactivity. In all species, uterine enzyme activity increased before implantation but decreased in the vicinity of the blastocyst once implantation had begun. A generalized increase over the entire length of the uterus was seen during the preimplantation phase in the uterine epithelium of the rabbit and in the endometrial stroma of the guinea-pig. Increase in stromal activity appeared to indicate predecidual transformations which were embryo-dependent (i.e. localized to the implantation site) in the rat, or embryoindependent (i.e. occurring throughout the uterus) in the guinea-pig. A subsequent decrease in enzyme activity occurred in the vicinity of the implanting embryo irrespective of the cell type involved (epithelium in the rabbit, stroma/decidua in the rat and guineapig). Since arylamidases of the type studied here are integrated membrane proteins, the uniformity of changes observed in different species may reflect profound changes in membrane properties of endometrial cells as an element of the implantation reaction.
\end{abstract}

Keywords: uterus; arylamidase; aminopeptidase; implantation; epithelium; stroma

\section{Introduction}

Arylamidases are believed to be sensitive markers for endometrial preparation for blastocyst implantation in the rabbit. Arylamidase $I$ is predominantly located at the apical surface of the luminal epithelium where blastocyst-uterine contact is initiated (Denker, 1977). The presence of an implantation-stage blastocyst results in localized depletion of enzyme activity in the epithelium immediately subjacent to the blastocyst (van Hoorn \& Denker, 1975). Arylamidases are secreted into the uterine fluid; the time of peak release coincides with the mid-point of the preimplantation period and enzyme secretion is responsive to ovarian steroid hormone treatment (Denker, 1980). Insertion of copper intrauterine devices results in localized depletion of epithelial arylamidase and inhibition of implantation (Denker, 1976). The present study was undertaken to determine whether similar patterns of uterine arylamidase localization and blastocyst-induced changes occur in the rat, hamster and guinea-pig. Preliminary results have been reported (Mitchell \& Denker, 1986).

\section{Materials and Methods}

Animals. Mature, virgin rabbits (mixed breed, $3.0-4.0 \mathrm{~kg})$, white rats $(250-300 \mathrm{~g})$, hamsters $(100-150 \mathrm{~g})$ and guineapigs (mixed breed, $600-650 \mathrm{~g}$ ) were used. Animals were maintained under controlled environmental conditions $(12 \mathrm{~h}$

*Present address: Department of Anatomy and Cell Biology, Wayne State University School of Medicine, Detroit, MI 48201, U.S.A. 
light $/ 12 \mathrm{~h}$ darkness; $23^{\circ} \mathrm{C}$ mean temperature; $50-60 \%$ humidity). Rabbits were housed singly; rats and hamsters were housed in clear plastic cages (4-6 animals); guinea-pigs were maintained in $4 \times 4 \mathrm{~m}$ pens (8-12 animals). All animals received a standard pellet diet and water was provided ad libitum. Guinea-pigs were provided with fresh vegetables.

Monitoring of reproductive cycles and breeding procedures. Reproductive cycles were monitored in rats by daily vaginal smears; in hamsters by periodic inspection for vaginal discharge and in guinea-pigs by inspection of the vaginal membrane for rupture and by vaginal lavage during pro-oestrus and oestrus. Pro-oestrous rats, hamsters and guinea-pigs were placed overnight with one or more males. The occurrence of copulation was indicated by the presence of a vaginal plug and/or by the detection of spermatozoa in the vaginal lavage. The day on which evidence of copulation was found was designated Day 1 of pregnancy. Does were mated with 2 fertile males; copulation was observed and the times of insemination noted (Day 0 of pregnancy).

Surgical procedures. All surgical procedures were performed under aseptic conditions. Rats, hamsters and guineapigs were anaesthetized with pentobarbitone $(40 \mathrm{mg} / \mathrm{kg}$ body weight, i.p.).

Detection of implantation sites and preparation of uterine tissue. Uteri were collected from pregnant animals during the peri-implantation period (rabbits: Days $5-8$ post coitum (p.c.): Day $5=120 \mathrm{~h}$ p.c.; rats: Days $5-6$ p.c.; hamsters: Days $4-6$ p.c., and guinea-pigs: Days 6-8 p.c.). Uteri were quickly removed and cut into segments of appropriate size $(2-3 \mathrm{~cm})$ for longitudinal sectioning. In rats, hamsters and guinea-pigs the location of implantation sites was determined by intravenous injection of Pontamine Blue dye (Psychoyos, 1960). After anaesthesia, an external jugular vein was exposed and $1.0 \mathrm{ml} 1.0 \%$ Pontamine Blue dye prepared in physiological saline $(9 \mathrm{~g} \mathrm{NaCl} / \mathrm{l})$ was injected intravenously. Injections were made at various times of day ranging from 09:00 to 24:00 h. At $15 \mathrm{~min}$ after dye injection, animals were laparotomized. The uterine cornua were removed, placed on an ice-cold glass plate and trimmed of adventitia. Each horn was inspected for implantation sites. The blue spots indicating areas of blastocyst implantation were counted and their location recorded in drawings. Such drawings permitted accurate correlation of histochemical reactivity with implantation site versus non-site areas of the uterus. Guinea-pig uteri generally required inspection with transillumination or reflected light to confirm the presence of dye spots. Uteri were sealed in plastic bags, immersed in liquid nitrogen and stored at $-60^{\circ} \mathrm{C}$ until processed for histochemical localization of arylamidase.

Histochemical localization of arylamidase activity. Areas of arylamidase activity were visualized by an azo dye method modified after Nachlas et al. (1962), using the substrate 1-leucine-4-methoxy- $\beta$-naphthylamide and Fast blue $B$ as the diazonium salt (Denker \& Stangl, 1976). Longitudinal cryostat sections $(14 \mu \mathrm{m})$ of uteri or uterine segments were prepared at approximately $-20^{\circ} \mathrm{C}$. Most sections were mounted on slides and used in their native state, but some sections were subjected to a freeze-substitution procedure (Glenner, 1962). To permit comparison of relative reaction intensity between species, tissue sections from different species were processed simultaneously.

Test for inhibition of arylamidase activity by Pontamine Blue dye. Endometrial arylamidase activity was measured in the presence of three different concentrations of Pontamine Blue dye $(2.5,0.25$ and $0.025 \mu \mathrm{g} / \mathrm{ml}$ saline $)$ and the dye vehicle (physiological saline). The $0.25 \mu \mathrm{g} / \mathrm{ml}$ concentration approximates the calculated level of dye carried into the incubation mixture by endometrial homogenate obtained after i.v. injection of $1.0 \mathrm{ml} 1.0 \%$ dye into a $550-\mathrm{g}$ guineapig. Endometrium was collected from 3 Day-7 p.c. guinea-pigs, frozen in liquid nitrogen and stored at $-60^{\circ} \mathrm{C}$ until analysed for enzyme activity.

Enzyme activity was determined in endometrial supernatants $(2500 \mathrm{~g})$ by using 1-leucine-4-nitroanilide $\left(10^{-3} \mathrm{M}\right)$ as substrate in veronal-acetate Michaelis buffer $\left(\mathrm{pH} \mathrm{7.2)}\right.$ with incubation for $30 \mathrm{~min}$ at $37^{\circ} \mathrm{C}$; increased absorbance was read at $405 \mathrm{~nm}$.

\section{Results}

\section{Histochemical localization of uterine arylamidase in interblastocyst segments}

The localization of arylamidase activity within the tissues comprising the uterus varied markedly between the species (Figs 1-9). In the rabbit, uterine arylamidase was localized primarily in the epithelial cells (Fig. 1), and to a lesser extent in blood vessels; little reactivity was observed in the myometrium. In epithelial cells, the enzyme was largely restricted to the apical region. Luminal epithelium and upper as well as middle parts of crypt epithelium showed a strong apical reaction, whereas deep parts of crypt epithelium exhibited little reactivity. The apical reaction appeared around Day 3 of pregnancy, reached a maximum at Day 5 p.c. and declined thereafter while the basolateral membrane region became more distinctly stained. Stromal cells exhibited only modest reactivity. In the hamster, arylamidase was also primarily localized in the luminal epithelium with an exceedingly intense reaction occurring along the luminal surface (Fig. 2). Typically, the epithelium was uniformly stained without any interruption of reactivity along its length (Fig. 8). Only moderate arylamidase localization was observed in the stroma and larger blood vessels; no significant staining 
was observed in glandular epithelium or myometrium. Similarly, in the rat the most intense staining reaction was restricted to the apical surface of the luminal epithelium although the reaction was not as strong as in the hamster or Day 5 rabbit uterus (Fig. 3). Reactivity in the luminal epithelium was variable; regions of intense reaction were interrupted by areas of reduced staining. The glandular epithelium, while clearly reactive, was generally stained less intensely than the cells bordering the lumen. Some moderately reactive cells occurred in the stroma but their distribution was heterogeneous. Blood vessels stained with intermediate intensity; the myometrium was essentially negative.

The tissue elements comprising the uterus of the guinea-pig differed markedly in arylamidase reactivity. The longitudinal and circular layers of myometrium were both virtually free of significant arylamidase staining (Fig. 6). By contrast, vascular elements were very rich in arylamidase (Figs 5,6). At lower magnification, the dense and intricate network of the uterine vasculature was readily apparent (Fig. 9). An extensive vascular zone divided the luminal from the peri-myometrial endometrial stroma. The glandular epithelium was devoid of arylamidase activity except around the basal part of the cytoplasm where modest reactivity was evident (Fig. 5). However, the immediately adjacent endometrial stroma including small blood vessels possessed strong reactivity. The intensity of staining in the endometrial stroma was quite marked but consistently less than that of blood vessels (Figs $4 \& 5$ ). The stroma was typically uniformly stained and the boundary between the adluminal part of the endometrial stroma and the subjacent vascular plexus was easily discerned (Fig. 9).

In contrast to the rabbit, rat and hamster, the luminal epithelium of the guinea-pig was virtually devoid of arylamidase reactivity (Fig. 4). While the glandular epithelium possessed modest reactivity in the basal cytoplasm (Fig. 5), the luminal epithelium was essentially without arylamidase reaction product (Figs $4 \& 5$ ). In the guinea-pig, therefore, maximum reactivity was observed in blood vessels; endometrial stroma was the second most reactive element.

\section{Changes in uterine arylamidase localization associated with blastocyst implantation}

In hamsters, rats and guinea-pigs, areas of the uterus in which blastocyst implantation was occurring were identified by means of the dye reaction and correlated with alterations in the distribution of arylamidase. Early stages of implantation were characterized by faint and somewhat diffuse Pontamine dye spots. With time, however, dye spots became more intense and well defined.

Implanting blastocysts induced marked alteration in the distribution of arylamidase in the uterus and the pattern of change differed between species (Figs 10-13). In the rabbit, epithelial arylamidase decreased much more quickly in the implantation chamber than in interblastocyst segments of the uterus. The strong apical reaction became depleted first at 6.6 days $(160 \mathrm{~h})$ p.c. at the luminal epithelium adjacent to the blastocyst, and later in the crypts. Differences between implantation chamber and interblastocyst epithelium became more obvious at 7 days $p . c$. and were very pronounced at 8 days p.c. (Fig. 10). There was a difference between the antimesometrial and mesometrial parts of the endometrium in so far as the apical reaction disappeared in the mesometrial region while it was still discernible (although decreased) antimesometrially, in the implantation chamber. The area of depletion increased with time as implantation advanced.

In the hamster, epithelial arylamidase staining was largely retained at the implantation site on Day 4, although there were always areas of the epithelium where the reaction was considerably weaker (Fig. 11). Occasionally, trophoblast attachment appeared in the areas of arylamidase depletion. However, it was not possible to establish a relationship between trophoblast attachment and changes in enzyme localization because of the limited morphological detail provided by cryostat sections. The majority of stromal cells remained low in reactivity although there were scattered individual cells of unknown identity (possibly macrophages) which were strongly stained. Such cells seemed to be numerous at implantation sites but quantification was not attempted.

In the rat, staining remained strong in the epithelium between implantation sites. Changes in arylamidase distribution associated with implantation were complex in this species (Fig. 12). 

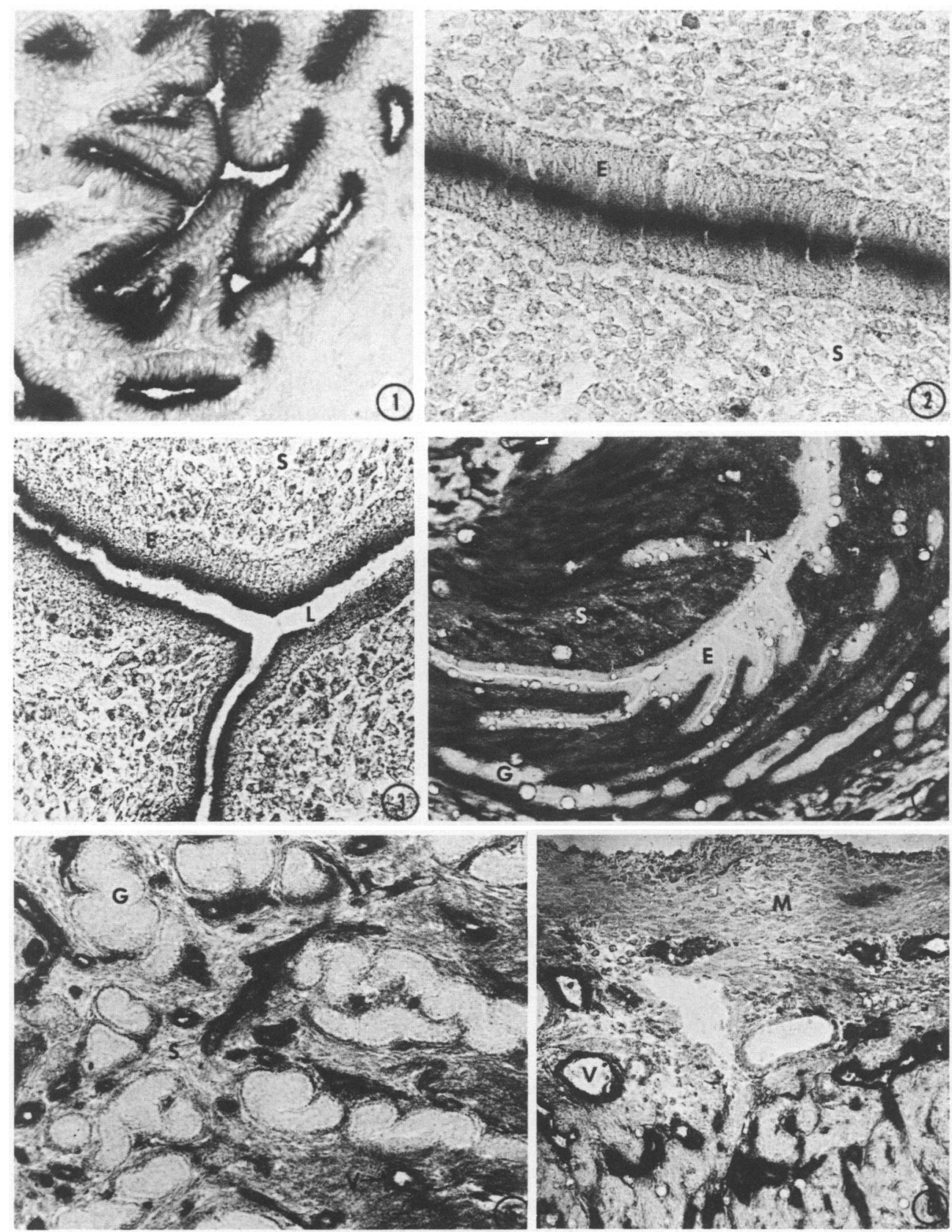
Arylamidase staining was clearly enhanced in the decidualized stroma situated peripherally to the implantation site. On the other hand, arylamidase content was depleted in the central region of decidualization close to the implanting blastocyst. By contrast, the non-decidualized stroma between sites remained unchanged, i.e. possessing only moderate intensity.

In the guinea-pig, arylamidase was markedly reduced in the stroma undergoing blastocystinduced decidualization (Fig. 13). Depletion was almost complete at the implantation site at Day 7. Arylamidase reactivity in non-decidualized stroma between sites, in blood vessels and in the myometrium was not altered.

Arylamidase activity was not altered by the presence of Pontamine Blue dye. Enzyme activity of endometrial homogenates was $96.8,96.9$ and $99.5 \%$ for samples containing $2.5,0.25$ and $0.025 \mu \mathrm{g}$ dye/ml, respectively (saline controls equal $100 \%$; mean values are for endometria obtained from 3 different animals). Therefore, it is assumed that the use of Pontamine Blue to render implantation sites visible had no effect on histochemical detection of arylamidase activity.

\section{Discussion}

The general distribution of histochemical arylamidase reactivity within the uterus differed between the species studied: arylamidase activity is localized primarily in the luminal epithelium in the rabbit, rat and hamster whereas enzyme activity is most abundant in the endometrial stroma in the guinea-pig. The rat takes a somewhat intermediate position in showing a marked activity at the luminal epithelium and in addition developing considerable activity in the peripheral part of decidualizing stroma. In the rabbit, uterine arylamidase activity is largely restricted to the apical aspect of epithelial cells during the peri-implantation phase (Denker, 1971; van Hoorn \& Denker, 1975). Yet, relative to the hamster, a graduation of enzyme localization was apparent within the rabbit epithelium: activity ranged from being merely detectable in the deep parts of endometrial crypts to intense at the luminal surface. By contrast, reactivity in the hamster uterus was almost

Fig. 1. Rabbit endometrium, Day 5 p.c. Arylamidase activity is very high at the apical surface of the uterine epithelium except for the deepest parts of endometrial crypts (lower right). Section freeze-substitution method, $\times 150$.

Fig. 2. The uterine luminal epithelium of a pregnant hamster (Day 5, a.m.) from a region between implantation sites. The intense localization of arylamidase along the apical surface of the epithelium is readily apparent; little reactivity is present in the non-decidualized endometrium. $\mathrm{E}=$ epithelium; $\mathrm{S}=$ stroma. Section freeze-substitution, $\times 250$.

Fig. 3. The uterine luminal epithelium in a region between implantation sites from a pregnant rat (Day 4, p.m.). The intensity of the apical localization varies along the length of the epithelium; undecidualized stroma possesses some moderate activity. $\mathrm{E}=$ epithelium; $\mathrm{S}=$ stroma; $\mathrm{L}=$ lumen. Native section, $\times 260$.

Fig. 4. The uterine luminal epithelium in a region distant from an implantation site from a pregnant guinea-pig (Day 7, p.m.). Vascular elements (upper left, lower right) are intensely stained, the stroma exhibits moderate and uniform staining, the luminal epithelium is devoid of reactivity. $\mathrm{E}=$ epithelium; $\mathrm{S}=$ stroma; $\mathrm{G}=$ gland; $\mathrm{L}=$ lumen. Native section, $\times 65$.

Fig. 5. Endometrial glands and stroma of a guinea-pig uterus (area between implantation sites). Arylamidase activity is prominent in vascular elements. Stroma and basal parts of gland epithelial cells are moderately stained. $S=$ stroma; $G=$ gland; $V=$ vessel. (Day 7, p.m.). Native section, $\times 250$.

Fig. 6. Myometrium of the guinea-pig (Day 7,p.m.). Note intensely stained vascular walls seen in longitudinal and cross section. $\mathbf{V}=$ vessel; $\mathbf{M}=$ myometrium. Native section, $\times 250$. 

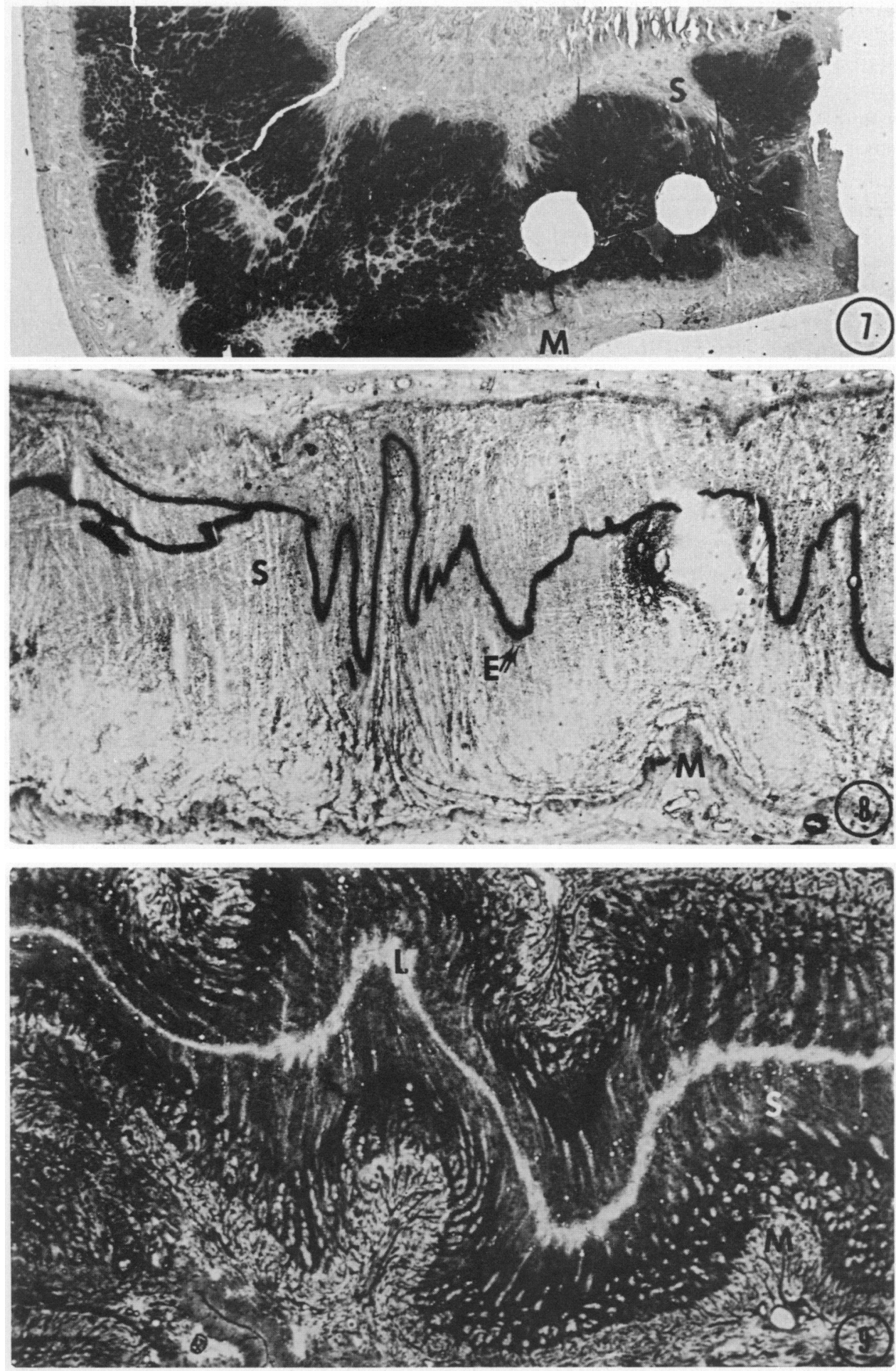
exclusively found in the luminal epithelium; glandular epithelium showed almost no staining. Similarly, the appearance of relatively meagre overall arylamidase reactivity in the endometrial stroma of the rat was due, in part, to the heterogeneity of localization; some stromal cells were moderately reactive whereas other adjacent cells were essentially free of reaction product. In contrast, virtually all stromal elements in the guinea-pig endometrium were strongly stained.

Comparison of tissue sections from different species processed together indicates that the apical histochemical reaction while abundant in the rabbit, was even more intense in the hamster. Similarly, whereas the stromal reaction was merely moderate in the rat, it was exceedingly intense in the endometrial stroma of the guinea-pig. Such marked differences in reaction intensity may indicate actual quantitative differences in enzyme concentration between species. However, speciesdependent factors such as differences in kinetic constants, $\mathrm{pH}$ optima and activating ion requirements may contribute to the observed differences in apparent enzyme activity. In addition, the relative abundance of various arylamidases may contribute to the apparent differences in the intensity of histochemical staining observed between species (Vanha-Perttula \& Hopsu, 1966; Denker \& Stangl, 1976; Denker, 1980; Lampelo et al., 1983a, b). Regardless of differences in reaction intensity, characteristic patterns of uterine localization were consistently apparent in the four species examined. Therefore, the rabbit, rat and hamster appear to be similar to the mouse in exhibiting primarily epithelial localization (Bergström, 1972) whereas the guinea-pig possesses, like the human, a stromal localization (Filipe \& Dawson, 1968).

The effects of blastocyst implantation on the distribution of uterine arylamidase also differed in detail between species although certain consistent features could be recognized. As previously shown the implanting rabbit blastocyst depletes arylamidase activity in the subjacent epithelium and stroma (van Hoorn \& Denker, 1975). However, such a decrease in epithelial reaction was not a consistent feature in the implantation chamber of the hamster. The limited morphological detail provided by the cryostat sections suggests but does not allow us to determine that a very localized arylamidase depletion occurs from those uterine epithelial cells in contact with trophoblast. On the other hand, arylamidase activity was markedly depleted around implantation sites in the guinea-pig (stromal cells). Typically, reduction in enzyme activity was most intense near the centre of the area of decidualization and decreased progressively toward the periphery of the decidual cell reaction. The depletion of arylamidase was particularly evident in the guinea-pig; decidualized endometrial stroma was virtually devoid of reaction product and thus stood out in marked contrast to the densely stained endometrium between implantation sites. The boundary between decidualized and nondecidualized cells was relatively distinct and progressed outward as implantation advanced. In contrast to the guinea-pig, the blastocyst-induced decidualizing cell reaction in the rat demonstrated

Fig. 7. Low magnification overview of longitudinal section of a rabbit uterus at Day 5 p.c. Two blastocysts can be recognized (empty circles). Cracks are due to the freeze-substitution method. Note the homogeneity of epithelial arylamidase reaction over the whole length of the section. At this early stage, there is no diminution of staining in the vicinity of the blastocysts. $\mathrm{S}=$ stroma; $\mathbf{M}=$ myometrium. $\times 10$.

Fig. 8. Hamster, low magnification view of a longitudinal section of uterus at Day 5 p.m. The arylamidase reaction of the luminal epithelium is strong and homogeneous over the whole length of the section. $\mathrm{E}=$ epithelium; $\mathrm{S}=$ stroma; $\mathrm{M}=$ myometrium. Native section, $\times 15$.

Fig. 9. Guinea-pig, low magnification view of a longitudinal section through the uterus (Day 7). The reaction of the endometrial stroma is homogeneous and strong over the whole length of this inter-blastocyst part of the uterus; it stands out clearly against the negative staining of the luminal epithelium (white band) and the low reactivity of glands. Note also the filigree-like pattern of strongly stained myometrial blood vessels. $\mathrm{L}=$ lumen; $\mathrm{M}=$ myometrium. Native section, $\times 15$. 

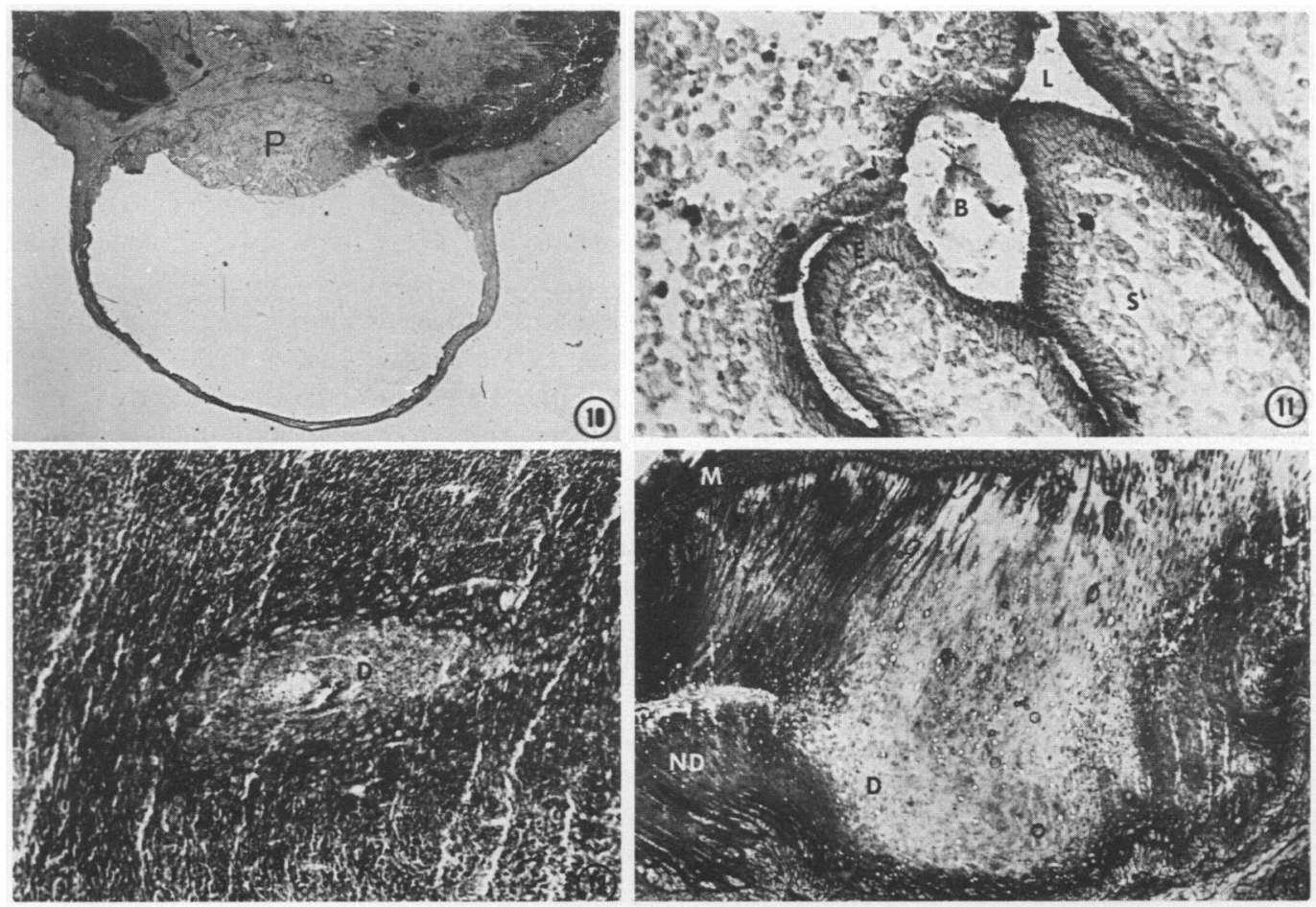

Fig. 10. Rabbit, low magnification overview of implantation site at Day 8 p.c., longitudinal section. Moderate arylamidase activity is still present in the uterine epithelium at interblastocyst segments but is depleted at the implantation site. $\mathbf{P}=$ placental fold. $\times 6$.

Fig. 11. Hamster, blastocyst site, Day 4, noon. Arylamidase activity is still high in the apical part of uterine epithelial cells (cf. Fig. 2) except for one part (lower left) where the trophoblast appears to have attached). A strong reaction occurs in a few scattered stromal cells (macrophages?), some of which seem to invade the epithelium ( 2 at upper left, 1 at lower right). B = blastocyst; $\mathbf{E}=$ epithelium; $\mathbf{S}=$ stroma $\mathbf{L}=$ lumen. Native section, $\times 195$.

Fig. 12. Rat, implantation site, Day 6, a.m. As compared to interblastocyst parts of the uterus (Fig. 3), arylamidase activity is markedly enhanced in decidualizing stroma cells at the periphery of the site. It is, on the other hand, low in the central parts of the decidua (close to the invading trophoblast). $\mathrm{D}=$ decidualized stroma; $\mathrm{ND}=$ non-decidualized stroma. Native section, $\times 70$.

Fig. 13. Guinea-pig, overview of implantation site region, Day 7 . Histochemical reactivity is much reduced in the endometrium undergoing blastocyst-induced decidualization. Endometrium adjacent to the region of decidual cell reaction remains strongly stained (cf. Fig. 9). $\mathrm{D}=$ decidualized stroma; ND = non-decidualized stroma; $M=$ myometrium. Native section, $\times 12$.

enhanced arylamidase activity. The surrounding non-decidualized stroma exhibited the typical heterogeneous distribution of moderately reactive cells. A similar enhancement of arylamidase activity at the implantation site also occurs in the mouse (Bergström, 1972). In the rat it was obvious, however, that decidual cells in the immediate vicinity of the implanting blastocyst, i.e. in the centre of the implantation site, showed decreased activity before degenerating. This change may be similar to the observed decrease in enzyme activity at guinea-pig implantation sites.

The functional significance of the differences in arylamidase localization within the uterus of various species and the meaning of the blastocyst-induced alterations in enzyme distribution remain to be decermined. The arylamidases are a broad group of aminopeptidase-type enzymes. The term 
arylamidase is used for those enzymes which show particularly high activity against arylamides, e.g. $\beta$-naphthylamides (see van Hoorn \& Denker, 1975; Denker \& Stangl, 1976). In non-purified material (e.g. tissue sections) most activity detected with leucine- $\beta$-naphthylamide is due to the membrane-bound aminopeptidase M (EC 3.4.11.2) (McDonald \& Schwabe, 1977).

Several functions have been proposed for the arylamidases. Arylamidase activity may serve as an indicator of increased cell activity (Pearse \& Tremblay, 1958; Talanti \& Hopsu, 1961; Dey et al., 1973) or tissue regression (Lobel et al., 1961; Hopsu et al., 1962; Gupta et al., 1973). With regard to specific functions in the female genital tract, changes in arylamidase activity associated with conversion of stromal cells into decidual cells suggest a role in cell proliferation (Gupta et al., 1973) and enhanced secretion of arylamidase into the uterine fluid during early pregnancy in the rabbit (Denker, 1980) suggests a possible role in blastocyst 'nutrition' (Beier, 1970), or the processing of proteins within the uterine lumen. Steroid hormone-dependent extrusion of arylamidases into the uterine fluid also occurs in the rat (Peplow, 1982) and in the pig and mare (Basha et al., 1978; Zavy et al., 1979, 1984).

The diversity of uterine arylamidase distribution between species, and the range of variation in blastocyst-evoked changes in localization of the enzyme suggest that uterine arylamidases serve quite diverse functions in different species. However, the dominant enzyme of this group detectable with the method employed, i.e. aminopeptidase $\mathbf{M}$, is an integral membrane protein (McDonald \& Schwabe, 1977). The observed uniformity of endometrial response at implantation sites, i.e. increase in enzyme activity followed by depletion, may reflect profound changes in plasma membrane composition of endometrial cells confronting the invading trophoblast.

This study was supported by a grant to H.-W.D. from the Deutsche Forschungsgemeinschaft (No. De 181/9-5) and by a fellowship to J.A.M. from the Alexander von Humboldt Stiftung.

\section{References}

Basha, S., Horst, M., Bazer, F. \& Roberts, R. (1978) Peptidases from pig reproductive tract: Purification and properties of aminopeptidases from uterine secretions, allantoic fluid and amniotic fluid. Archs Biochem. Biophys. 185, $174-184$.

Beier, H. (1970) Hormonal stimulation of protease inhibitor activity in endometrial secretion during early pregnancy. Acta endocr., Copenh. 63, 141-149.

Bergström, S. (1972) Histochemical localization of acid uterine aminoacylnaphthylamidases in early pregnancy and in different hormonal states of the mouse. J. Reprod. Fert. 30, 177-183.

Denker, H.-W. (1971) Zur Enzym-Topochemie von Frühentwicklung und Implantation des Kaninchens III. Proteasen. Histochemie 25, 344-360.

Denker, H.-W. (1976) Copper IUD-induced loss of endometrial arylamidase activity in the rabbit. Biol. Reprod. 15, 519-522.

Denker, H.-W. (1977) Implantation: the role of proteinases and blockage of implantation by proteinase inhibitors. Adv. Anat. Embryol. Cell Biol. 53, fasc. 5.

Denker, H.-W. (1980) Endometrial arylamidase secretion: a sensitive parameter of steroid hormone action and of embryo-maternal interrelationships in the rabbit. In Steroid Induced Uterine Proteins, pp. 121-131. Ed. M. Beato. Elsevier, Amsterdam.

Denker, H.-W. \& Stangl, R. (1976) Versuche zur Lokalisierung und Abgrenzung verschiedener AminosäureArylamidasen in Uterus and Blastozyste des Kaninchens. Acta histochem., Suppl. 16, 249-257.
Dey, S.,'Gupta, J. \& Deb, C. (1973) Histochemical studies on the Leydig-cell leucine aminopeptidase activity in the guinea-pig testis. $J$. Reprod. Fert. 34, 475-479.

Filipe, M. \& Dawson, I. (1968) Qualitative and quantitative enzyme histochemistry of the human endometrium and cervix in normal and pathological conditions. $J$. Path. Bact. 95, 243-250.

Glenner, G. (1962) The preservation of peptidase activity localization using $\beta$-naphthylamide substrates. $J$. Histochem. Cytochem. 10, 257-258.

Gupta, J., Dey, S. \& Deb, C. (1973) Histochemical studies on leucine aminopeptidase activity in the rat uterus. J. Reprod. Fert. 34, 467-473.

Hopsu, V., Riekkinen, P. \& Loustarinen, E. (1962) Hormonal influences on leucine aminopeptidase in the accessory reproductive tracts of the rat. Experientia 15, 15-17.

Lampelo, S., Lalu, K. \& Vanha-Perttula, T. (1983a) Characterization of two thiol-dependent aminopeptidases partially purified from human placenta. Int. J. Biochem. 15, 709-714.

Lampelo, S., Lalu, K. \& Vanha-Perttula, T. (1983b) Characterization of three aminopeptidases purified from human placenta. Placenta 4, 499-514.

Lobel, B., Rosenbaum, R. \& Deane, H. (1961) Enzymatic correlates of physiological regression of follicles and corpora lutea in ovaries of normal rats. Endocrinology 68, 232-247.

McDonald, J. \& Schwabe, C. (1977) Intracellular exopeptidases. In Proteinases in Mammalian Cells and 
Tissues, pp. 311-391. Ed. A. J. Barrett. NorthHolland Publishing Co., Amsterdam.

Mitchell, J. \& Denker, H.-W. (1986) Implantationinduced changes in uterine arylamidase localization in the rabbit, rat, hamster and guinea pig. Biol. Reprod. 34, Suppl. 1, 103, Abstr.

Nachlas, M., Goldstein, T. \& Seligman, A. (1962) An evaluation of aminopeptidase specificity with seven chromogenic substrates. Archs Biochem. Biophys. 97, 223-231.

Pearse, A. \& Tremblay, G. (1958) Leucine aminopeptidase in rat parathyroid and its relation to parathyroid hormone production. Nature, Lond. 181, 1532-1533.

Peplow, P. (1982) Analysis of endopeptidase and arylamidase enzymes in uterine fluid of oestrogen-treated rats. J. Reprod. Fert. 66, 649-654.

Psychoyos, A. (1960) La réaction déciduale est précedée de modifications précoces de la perméabilité capillarie de l'utérus. C. r. Séanc. Soc. Biol. 154, 1384-1387.
Talanti, S. \& Hopsu, V. (1961) Leucine aminopeptidase in the gastric mucosa of the adrenalectomized rat. Endocrinology 68, 184-185.

Vanha-Perttula, T. \& Hopsu, V. (1966) The ovarian enzymes hydrolysing L-leucyl- and DL-alanyl- $\beta$ naphthylamide. Histochemie 6, 3445.

Van Hoorn, G. \& Denker, H.-W. (1975) Effect of the blastocyst on a uterine amino acid arylamidase in the rabbit. J. Reprod. Fert. 45, 359-362.

Zavy, M., Roberts, R. \& Bazer, F. (1984) Acid phosphatase and leucine aminopeptidase activity in the uterine flushings of non-pregnant and pregnant gilts. J. Reprod. Fert. 72, 503-507.

Zavy, M., Bazer, F., Sharp, D. \& Wilcox, C. (1979) Uterine luminal proteins in the cycling mare. Biol. Reprod. 20, 689-698.

Received 18 September 1987 